\title{
A Comparative Study of the Effects of Aerobic and Resisted Exercises on Selected Cardiopulmonary Parameters in Patients with Asthma
}

\author{
Aweto, H.A., Akodu, A.K., Adedara, A.C., Olawale, O.A. \\ Department of Physiotherapy, College of Medicine, University of Lagos \\ Correspondence: \\ Happiness Anulika Aweto, Department of Physiotherapy, College of Medicine, University of Lagos, PMB \\ 12003, Idi-Araba, Lagos State, Nigeria•E-mail: awetohappiness@gmail.com; haweto@unilag.edu.ng
}

\begin{abstract}
SUMMARY
Asthma is a multi-factorial disease associated with genetic, allergic, environmental, infectious, emotional, and nutritional issues. Globally, asthma affects about 300 million people and about 250,000 people die from it every year. These deaths are related to lack of proper treatment. Treatment involves controlling trigger factors, drug therapy, and other non-pharmacological methods. Although a few studies have evaluated the effects of exercises on asthma control, there is the need for well-designed outcome studies that will differentiate efficacious exercise management for asthma from those that hold little therapeutic value. This study compared the effects of aerobic and resisted exercises on selected cardiopulmonary parameters in patients with asthma.

Forty-five patients with asthma were recruited from the Respiratory Unit, Department of Medicine, Lagos University Teaching Hospital (LUTH), Lagos and were randomly assigned to 3 different groups. Group A underwent aerobic exercise and counselling sessions; Group B, resisted exercise and counselling sessions; and Group C had counselling sessions only. Groups A and B had exercise intervention that lasted 10-15 minutes, twice weekly for 6 weeks. Cardiopulmonary parameters were assessed at baseline and at the end of 6 weeks.

Only Group B showed significant improvements in all the cardiovascular variables $(\mathrm{SBP}: \mathrm{p}=0.01, \mathrm{DBP}$ : $p=0.03$, HR: $p=0.02$ and RPP: $p=0.01)$. There were also significant improvements in most of the pulmonary variables of Group A ( R R: p = 0.01, FEV $: p=0.01, F V C: p=0.01$ and FEV $\%: p=0.02)$, however, there was none in Groups B and C. Comparison of the mean changes in selected variables between the two therapeutic exercise groups showed significant differences in $\operatorname{SBP}(p=0.01), \operatorname{DBP}(p=0.04), \operatorname{RPP}(p=0.02), \operatorname{RR}(p=0.01), \operatorname{FEV}$, $(p=0.01)$, FVC $(p=0.05), \mathrm{FEV}_{1} \%(\mathrm{p}=0.01)$ and $\mathrm{IC}_{(\mathrm{p}=0.05)}$.

Aerobic exercise was more effective in improving pulmonary parameters while resisted exercise was more effective in improving cardiovascular parameters in patients with asthma.
\end{abstract}

KEY WORDS: aerobic exercise, asthma, cardiopulmonary, resisted exercise

\section{INTRODUCTION}

The word 'asthma' is derived from the Greek word "azein" which means 'breathe hard'. It is a chronic inflammatory disorder of the respiratory airways, characterized by increased mucus production, airway hyper-responsiveness and variable airflow obstruction (Global Initiative on Asthma [GINA], 2012). It is often reversible spontaneously or following treatment (GINA, 2012). Symptoms and signs include dyspnoea, chest tightness, cough, and wheezing. Acute symptoms of asthma usually arise from bronchospasm. Acute and chronic inflammation can affect not only the airway caliber and airflow, but also underlying bronchial hyper-responsiveness, which increases susceptibility to broncho-spasm (Cohen et al, 2004). The 
majority of individuals with asthma miss a significant number of days of work or school because of the symptoms of the disorder. This creates a severe disruption in activities of daily living, often leading to depressive episodes (Stores et al, 1998; Lavoie et al, 2005). It also disrupts the lives of caregivers and family members. Patients with asthma who have increased symptoms at night also tend to have disturbed sleep patterns and impaired daytime attention, concentration, and memory (Stores et al, 1998).

Asthma is a multi-factorial disease associated with genetic, allergic, environmental, infectious, emotional, and nutritional issues. Its incidence increases worldwide as communities adopt modern lifestyles and become urbanized (Janson, 2004). Industrialization of countries and the use of fossil fuels have paralleled the incidence of respiratory diseases. Changes in diet, including decreased intake of nutrients such as magnesium, and altered intestinal microflora are also hypothesized as contributors to the increased incidence of asthma (Parronchi et al, 2006). Active smokers have more severe asthma symptoms, an accelerated decline in lung function, and a reduced response to corticosteroid therapy (Cohen et al, 2004; Beeh, 2006).

Globally, asthma affects about 300 million people and about 250,000 people die from it every year (GINA, 2012). These deaths are related to lack of proper treatment. Treatment involves controlling trigger factors, drug therapy, and other non-pharmacological methods (Sullivan et al, 2007). Since the introduction of pharmacological interventions for the control of asthma symptoms, interest in non-pharmacological methods has declined (Sullivan et al, 2007). Prognosis is good with treatment coupled with pulmonary rehabilitation (Russell et al, 2008). Pulmonary rehabilitation has largely been limited to patients with chronic obstructive pulmonary disease (COPD), but there is now a recognition that other patient groups may benefit because the principles are the same, but with some additional consideration (Russell et al, 2008). Although a number of studies have evaluated the effects of exercises, especially aerobic exercise, on asthma control, there is still the need for well-designed outcome studies that will better define efficacious exercise management for asthma. This study therefore compared the effects of aerobic and resisted exercises on selected cardiopulmonary parameters in patients with asthma.

\section{METHOD}

\section{Subject Selection}

Forty-five (45) patients with asthma were recruited from the Respiratory Unit of the Department of Medicine, Lagos University Teaching Hospital (LUTH), Idi-Araba, Lagos State, Nigeria. They were randomly assigned to 3 different groups (A, B and C) using the fish bowl technique where the number the subjects picked determined their group. Group A (Aerobic group) was made up of 7 males and 8 females, Group B (Resisted group) was made up of 9 males and 6 females while Group C (Control group) was made of 8 males and 7 females. The subjects recruited for the study were patients diagnosed with asthma according to GINA guidelines, who had not smoked for at least one year. They were clinically stable and were without acute exacerbation of asthma or respiratory tract infection in the preceding 6 weeks. Their ages ranged from 18 to 48 years. Excluded from the study were: patients whose diagnosis of asthma was uncertain; patients with very severe asthma and whose condition would constitute a considerable risk if they exercised; patients with other lung diseases; and patients with contraindications to exercise such as dyspnoea, fainting, tiredness, and dizziness. Ethical approval was obtained from the Health Research and Ethics Committee of Lagos University Teaching Hospital, Idi-Araba, Lagos State, Nigeria (REF.NO: ADM/DCST/HREC/VOL.XVI/ APP/800). Written informed consent was obtained from subjects who participated in the study.

\section{Procedure for data collection}

The study was carried out at the Out-Patient Clinic of the Physiotherapy Department, Lagos University Teaching Hospital, Idi-Araba, Lagos. Assessments were carried out between 9:00 am and 12:00 noon after 15 minutes of rest (Andersen et al., 2010). This was to maintain the same environmental conditions and also allow the cardiopulmonary functions of subject to return to resting state. The baseline values of selected cardiopulmonary parameters were measured and recorded for each subject prior to the interventions. The height and weight of each subject were also measured at baseline using a height meter and weighing scale respectively. All subjects were educated on Borg's scale of perceived exertion. The outcome measures were taken at baseline and at the end of the $6^{\text {th }}$ week and these included: heart rate (HR), systolic blood 
pressure (SBP), diastolic blood pressure (DBP) and rate product pressure (RPP) for cardiovascular parameters while pulmonary parameters were respiratory rate (RR), peak expiratory flow rate (PEFR), forced expiratory volume in 1 second $\left(\mathrm{FEV}_{1}\right)$, forced vital capacity $(\mathrm{FVC})$, forced expiratory volume percent $\left(\mathrm{FEV}_{1} \%\right)$ and inspiratory capacity (IC). The SBP and DBP were measured with a mercury sphygmomanometer and a stethoscope in sitting position, and HR with a stethoscope; RPP is the product of SBP and HR. The FVC and $\mathrm{FEV}_{1}$ were measured with a hand-held spirometer, PEFR with a peak flow rate meter and IC with a volumetric exerciser.

\section{Interventions for the Study Groups}

\section{Study Group A}

Therapeutic exercise mode: Aerobic exercise using the treadmill.

Therapeutic exercise intensity: The intensity of aerobic exercise was moderate, which was equivalent to the subject's target heart rate (THR), determined using Karvonen's formula:

$\mathrm{THR}=0.6(\mathrm{MHR}-\mathrm{HR}$ at rest $)+\mathrm{HR}$ at rest $($ Tanaka et al, 2001)

where: $\mathrm{MHR}=$ maximal heart rate

$$
\mathrm{HR}=\text { heart rate }
$$

The formula for calculating MHR for females is (226 - age in years); and for males (220 - age in years) (Bumgardner, 2008). Since MHR - HR at rest $=$ Heart rate reserve (HRR), another formula for THR is:

$\mathrm{THR}=($ HRR $\times 0.6)+\mathrm{HR}$ at rest $($ Tanaka et al, 2001).

Therapeutic exercise intervention for subjects in this group was done in 3 phases namely, warm-up, aerobic exercise, and cool down. The warm-up and cool down phases were for 5 minutes each and consisted of breathing exercises, stretching exercises, and walking around the gymnasium at normal speed.

Therapeutic exercise duration: The subjects exercised for 10 minutes for the first 4 weeks then 15 minutes for the last 2 weeks.

Therapeutic exercise frequency: Exercise was performed 2 times a week for 6 weeks.

\section{Study Group B}

Therapeutic exercise mode: Resisted exercise (i.e. lifting dumbbells of different weights)

Therapeutic exercise intensity: Each subject's one repetition maximum (1 RM) was assessed. This was the maximum weight which each subject could lift once only through a prescribed range. Resisted exercise was done at moderate intensity which was equivalent to exercising at 50-70 percent of $1 \mathrm{RM}$. Subjects were instructed to lift a dumbbell weight 50-70 percent of 1 RM four times within a period of 20 to 30 seconds. Twelve lifting repetitions were done per set until the end of the intervention period. Lifting the dumbbell includes lifting it from the ground to the waist then from the waist to the shoulder level.

Therapeutic exercise duration: These subjects exercised for 10 minutes in the first 4 weeks and 15 minutes in the last two weeks.

Therapeutic exercise frequency: Exercise was performed 2 times a week for 6 weeks.

\section{Study group C}

This is the control group. This group did not carry out any therapeutic exercise but participated in counselling and educational sessions with subjects from other groups.

The counselling and educational sessions were for 15 minutes, once a week for 6 weeks.

\section{Data Analysis}

All statistical tests were done using the Statistical Package for Social Sciences (SPSS) version 17 (Chicago, IL). All demographic and quantitative data were expressed as mean $(\bar{x})$ and standard deviation (SD). Analysis of variance (ANOVA) was used to compare demographic variables across groups. Paired $t$-tests were used to determine the significance of the differences between the mean values and changes in cardiopulmonary variables within each group and between intervention groups. Analysis of variance was also used to determine the significance of the differences in mean changes in the cardiopulmonary variables across groups. A least significant difference post-hoc test was used to determine the exact points where the significant variables became significant and the exclusively significant group. Significant level was put at $\mathrm{p} \leq 0.05$. 


\section{RESULTS}

A total of 45 (forty-five) subjects were recruited but fortytwo (42) completed the study. Distance and nature of occupation were the reasons given by the subjects for not completing the study.

Analysis of variance (ANOVA) showed that there was no significant difference in the physical characteristics of subjects in the three groups (Age: $\mathrm{p}=0.25$; $\mathrm{BMI}: \mathrm{p}=$ 0.42) (table 1).

Following the 6 weeks of study, paired $t$-test comparison of pre- and post-intervention mean cardiovascular scores showed significant changes in the SBP ( $p=0.01)$, DBP ( $=0.03)$, HR $(p=0.02)$ and RPP $(\mathrm{p}=0.01)$ of subjects in group B while those of groups A and $\mathrm{C}$ were not significant (table 2).

The paired $t$-test comparison of pre- and postintervention mean pulmonary scores showed significant changes in the RR $(p=0.01)$, FEV $_{1}(p=0.01), \quad$ FVC $(\mathrm{p}=0.01)$ and $\mathrm{FEV}_{1} \%(\mathrm{p}=0.02)$ of subjects in group $\mathrm{A}$ while those of groups $\mathrm{B}$ and $\mathrm{C}$ were not significant (table 3).

Table 4 shows a comparison of the mean changes in the cardiopulmonary variables between groups A and B. Paired $t$-test analysis showed that SBP $(\mathrm{p}=0.01), \operatorname{DBP}(\mathrm{p}=0.04)$, RPP $(p=0.02), \quad R R(p=0.01), F_{1}(p=0.01), \quad F V C$ $(p=0.05), \quad$ FEV $_{1} \% \quad(p=0.01)$ and IC $(p=0.05)$ were significant while other variables were not.

Table 5 shows a comparison of the mean changes in cardiopulmonary variables across the 3 groups. ANOVA showed that there were significant changes in SBP $(p=0.01), \operatorname{DBP}(p=0.05), \operatorname{HR}(p=0.01)$, FVC $(p=0.01)$, $\mathrm{FEV}_{1}(\mathrm{p}=0.03), \operatorname{FEV}_{\%}(\mathrm{p}=0.01)$, and IC $(\mathrm{p}=0.01)$ but other selected variables were not significant.

Post-hoc analysis shows that significant changes in SBP, DBP, HR, FVC, $\mathrm{FEV}_{1}, \mathrm{FEV} \%$, and IC occurred between groups $\mathrm{A}$ and $\mathrm{B}, \mathrm{A}$ and $\mathrm{C}, \mathrm{B}$ and $\mathrm{C}$ (table 5).

Table 1. Physical characteristics of the subjects

\begin{tabular}{|c|c|c|c|c|}
\hline Study- Group & $\begin{array}{c}\text { Age }(\mathrm{yrs}) \\
\bar{X} \pm \mathrm{SD}\end{array}$ & $\begin{array}{c}\text { W eight }(\mathrm{kg}) \\
\overline{\mathrm{X}} \pm \mathrm{SD}\end{array}$ & $\begin{array}{c}\text { Height (m) } \\
\bar{X} \pm \mathrm{SD}\end{array}$ & $\begin{array}{c}\mathrm{BMI}\left(\mathrm{kg} / \mathrm{m}^{2}\right) \\
\bar{X} \pm \mathrm{SD}\end{array}$ \\
\hline A & $24.53 \pm 6.41$ & $71.73 \pm 7.29$ & $172.47 \pm 7.34$ & $24.22 \pm 3.45$ \\
\hline $\mathrm{B}$ & $26.17 \pm 11.19$ & $79.60 \pm 29.14$ & $168.47 \pm 4.78$ & $20.07 \pm 5.37$ \\
\hline $\mathrm{C}$ & $27.47 \pm 8.41$ & $67.27 \pm 5.18$ & $174.67 \pm 6.24$ & $21.95 \pm 2.17$ \\
\hline ANOVA & 27.48 & 20.21 & 61.6 & 18.40 \\
\hline p-value & 0.25 & 0.22 & 0.23 & 0.42 \\
\hline
\end{tabular}

Key: ANOVA $=$ Analysis of Variance

Table 2. Comparison of changes in cardiovascular variables between pre-intervention (baseline) and post-intervention $\left(6^{\text {th }}\right.$ week)

\begin{tabular}{|c|c|c|c|c|c|}
\hline $\begin{array}{l}\text { Study } \\
\text { Group }\end{array}$ & Cardiovascular Variables & $\begin{array}{l}\text { Pre-intervention } \\
\text { (Baseline) } \\
\bar{X} \pm \mathrm{SD}\end{array}$ & $\begin{array}{c}\text { Post- intervention } \\
\text { (End of } 6 \text { weeks) } \\
\quad \bar{X} \pm \mathrm{SD}\end{array}$ & t-value & p-value \\
\hline \multirow[t]{4}{*}{ A } & $\mathrm{SBP}(\mathrm{mmHg})$ & $123.80 \pm 15.37$ & $119.27 \pm 11.37$ & 0.92 & 0.37 \\
\hline & $\mathrm{DBP}(\mathrm{mmHg})$ & $83.33 \pm 14.65$ & $83.13 \pm 10.42$ & 0.04 & 0.96 \\
\hline & $\mathrm{HR}$ (beats/min) & $96.73 \pm 9.94$ & $92.80 \pm 9.61$ & 1.10 & 0.28 \\
\hline & $\mathrm{RPP}($ beats $/ \mathrm{min} / \mathrm{mmHg}$ ) & $11975.17 \pm 1922.12$ & $11068.26 \pm 1586.35$ & 0.69 & 0.49 \\
\hline \multirow[t]{4}{*}{ B } & $\mathrm{SBP}(\mathrm{mmHg})$ & $130.20 \pm 13.57$ & $112.57 \pm 10.65$ & 3.54 & $0.01 *$ \\
\hline & $\mathrm{DBP}(\mathrm{mmHg})$ & $96.00 \pm 14.31$ & $85.62 \pm 8.28$ & 2.28 & $0.03 *$ \\
\hline & $\mathrm{HR}$ (beats/min) & $102.50 \pm 14.73$ & $91.00 \pm 9.70$ & 2.37 & $0.02 *$ \\
\hline & $\mathrm{RPP}($ beats/min/mmHg) & $13345.50 \pm 1774.87$ & $10243.87 \pm 1759.34$ & 2.59 & $0.01 *$ \\
\hline \multirow[t]{4}{*}{$\mathrm{C}$} & $\mathrm{SBP}(\mathrm{mmHg})$ & $124.20 \pm 13.06$ & $120.84 \pm 12.10$ & 0.42 & 0.69 \\
\hline & $\mathrm{DBP}(\mathrm{mmHg})$ & $91.73 \pm 11.20$ & $86.85 \pm 10.38$ & 0.65 & 0.53 \\
\hline & HR(beats/min) & $94.60 \pm 9.11$ & $102.46 \pm 8.20$ & 2.87 & 0.09 \\
\hline & $\mathrm{RPP}($ beats/min/mmHg) & $11749.22 \pm 184.23$ & $12381.27 \pm 1820.07$ & 0.93 & 0.52 \\
\hline
\end{tabular}

*Significant difference at $\mathrm{p} \leq 0.05$

Key: $\overline{\mathrm{X}} \pm \mathrm{SD}=$ Mean \pm Standard deviation; SBP $=$ Systolic Blood Pressure; DBP $=$ Diastolic Blood Pressure RPP $=$ Rate Product Pressure; HR $=$ Heart Rate; $\mathrm{A}=$ Aerobic exercise group; $\mathrm{B}=$ Resisted exercise group; $\mathrm{C}=\mathrm{Control}$ group; $\mathrm{t}$-value $=$ Paired t test 
Table 3. Comparison of changes in pulmonary variables between pre-intervention (baseline) and post-intervention ( $6^{\text {th }}$ week)

\begin{tabular}{|c|c|c|c|c|c|}
\hline $\begin{array}{l}\text { Study } \\
\text { Groups }\end{array}$ & Pulmonary Variables & $\begin{array}{l}\text { Pre-intervention } \\
\qquad \begin{array}{c}\text { (Baseline) } \\
\overline{\mathrm{X}}_{ \pm \mathrm{SD}}\end{array}\end{array}$ & $\begin{array}{l}\text { Post- intervention } \\
\text { (End of } 6 \text { weeks) } \\
\overline{\mathrm{X}}_{ \pm \mathrm{SD}}\end{array}$ & t-value & p-value \\
\hline \multirow[t]{6}{*}{ A } & $\mathrm{RR}$ (counts/min) & $19.27 \pm 2.3$ & $16.53 \pm 2.10$ & 8.27 & $0.01 *$ \\
\hline & $\operatorname{PEFR}(\mathrm{L} / \mathrm{min})$ & $214.40 \pm 74.66$ & $242.74 \pm 62.77$ & 4.43 & 0.27 \\
\hline & $\mathrm{FEV}_{\mathrm{I}}(\mathrm{L})$ & $0.83 \pm 0.28$ & $1.24 \pm 0.30$ & 9.11 & $0.01 *$ \\
\hline & $\mathrm{FVC}(\mathrm{L})$ & $1.52 \pm 0.35$ & $1.92 \pm 0.32$ & 5.60 & $0.01 *$ \\
\hline & $\mathrm{FEV}_{1} \%$ & $56.33 \pm 10.80$ & $64.60 \pm 8.02$ & 6.12 & $0.02 *$ \\
\hline & $\mathrm{IC}(\mathrm{mL})$ & $1470.01 \pm 767.14$ & $1806.67 \pm 626.18$ & 4.63 & 0.19 \\
\hline \multirow[t]{6}{*}{ B } & $\mathrm{RR}$ (counts/min) & $17.21 \pm 2.51$ & $15.84 \pm 1.77$ & 1.62 & 0.11 \\
\hline & $\operatorname{PEFR}(\mathrm{L} / \mathrm{min})$ & $188.40 \pm 94.46$ & $205.76 \pm 81.39$ & 0.52 & 0.61 \\
\hline & $\mathrm{FEV}_{\mathrm{I}}(\mathrm{L})$ & $0.99 \pm 0.40$ & $1.17 \pm 0.29$ & 1.32 & 0.19 \\
\hline & $\mathrm{FVC}(\mathrm{L})$ & $1.58 \pm 0.40$ & $1.82 \pm 0.36$ & 1.64 & 0.11 \\
\hline & $\mathrm{FEV}_{1} \%$ & $59.14 \pm 10.73$ & $63.08 \pm 10.58$ & 0.95 & 0.34 \\
\hline & $\mathrm{IC}(\mathrm{mL})$ & $1786.43 \pm 836.82$ & $1934.62 \pm 640.11$ & 0.51 & 0.61 \\
\hline \multirow[t]{6}{*}{$\mathrm{C}$} & $\mathrm{RR}($ counts/min) & $17.27 \pm 2.25$ & $17.84 \pm 2.97$ & 0.33 & 0.70 \\
\hline & $\operatorname{PEFR}(\mathrm{L} / \mathrm{min})$ & $208.31 \pm 38.31$ & $187.92 \pm 70.81$ & 0.87 & 0.63 \\
\hline & $\mathrm{FEV}_{\mathrm{I}}(\mathrm{L})$ & $0.86 \pm 0.31$ & $1.08 \pm 0.35$ & 1.63 & 0.12 \\
\hline & $\mathrm{FVC}(\mathrm{L})$ & $1.61 \pm 0.49$ & $1.80 \pm 0.41$ & 1.03 & 0.31 \\
\hline & $\mathrm{FEV}_{1} \%$ & $55.67 \pm 12.40$ & $60.23 \pm 23.00$ & 0.61 & 0.55 \\
\hline & $\mathrm{IC}(\mathrm{mL})$ & $2033.01 \pm 859.69$ & $1892.31 \pm 793.16$ & 0.48 & 0.98 \\
\hline
\end{tabular}

*Significant difference at $\mathrm{p} \leq 0.05$

Key: $\bar{x} \pm \mathrm{SD}=$ Mean \pm Standard Deviation; $\mathrm{RR}=$ Respiratory Rate; PEFR $=$ Peak Expiratory Flow Rate; FEV ${ }_{1}=$ Forced expiratory volume in 1 second; $\mathrm{FVC}=$ Forced Vital Capacity; $\mathrm{FEV}_{1} \%=\mathrm{FEV} / \mathrm{FVC}$ percent; IC = Inspiratory Capacity; $\mathrm{A}=$ Aerobic exercise group; $\mathrm{B}=$ Resisted exercise group; $\mathrm{C}=$ Control group; $\mathrm{t}$-value $=$ Paired $\mathrm{t}$ test

Table 4. Comparison of the mean changes in cardiopulmonary variables of Groups A and B

\begin{tabular}{|c|c|c|c|c|}
\hline \multirow[t]{2}{*}{ Variables } & A & B & t-value & \multirow[t]{2}{*}{$\mathrm{p}$ - value } \\
\hline & Mean changes & Mean changes & & \\
\hline \multicolumn{5}{|l|}{ Cardiovascular } \\
\hline SBP $(\mathrm{mmHg})$ & 4.53 & 17.63 & 2.77 & $0.01 *$ \\
\hline $\mathrm{DBP}(\mathrm{mmHg})$ & 0.20 & 10.77 & 2.13 & $0.04 *$ \\
\hline HR (beats/min) & 3.93 & 10.38 & 1.36 & 0.18 \\
\hline $\mathrm{RPP}$ (beats $/ \mathrm{min} / \mathrm{mmHg}$ ) & 906.91 & 3101.63 & 2.18 & $0.02 *$ \\
\hline \multicolumn{5}{|l|}{ Pulmonary } \\
\hline RR (counts/min) & 2.73 & 1.38 & 2.91 & $0.01 *$ \\
\hline PEFR (L/min) & 28.34 & 17.62 & 0.95 & 0.35 \\
\hline $\mathrm{FEV}_{1}(\mathrm{~L})$ & 0.41 & 0.18 & 3.18 & $0.01 *$ \\
\hline FVC (L) & 0.40 & 0.24 & 2.18 & $0.05^{*}$ \\
\hline $\mathrm{FEV}_{1} \%$ & 9.97 & 1.63 & 2.94 & $0.01 *$ \\
\hline IC $(\mathrm{mL})$ & 336.66 & 148.18 & 2.13 & $0.05^{*}$ \\
\hline
\end{tabular}

*Significant difference at $\mathrm{p} \leq 0.05$

Key: $\mathrm{SBP}=$ Systolic Blood Pressure; DBP $=$ Diastolic Blood Pressure RPP $=$ Rate Product Pressure; HR $=$ Heart Rate; A = Aerobic exercise group; $\mathrm{B}=$

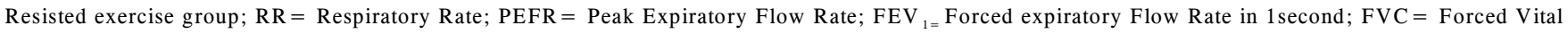
Capacity; FEV \% = FEV/FVC percent; IC $=$ Inspiratory Capacity; $\mathrm{t}$-value $=$ Unpaired $\mathrm{t}$ test 
Table 5. Comparison of the mean changes in cardiopulmonary variables across the 3 groups

\begin{tabular}{|c|c|c|c|c|c|c|}
\hline \multirow{3}{*}{ Variables } & \multicolumn{3}{|c|}{ Groups } & \multirow{3}{*}{ ANOVA } & \multirow{3}{*}{ p-value } & \multirow{3}{*}{ Post hoc } \\
\hline & A & $\mathrm{B}$ & $\mathrm{C}$ & & & \\
\hline & Mean changes & Mean changes & Mean changes & & & \\
\hline \multicolumn{7}{|l|}{ Cardiovascular } \\
\hline $\mathrm{SBP}(\mathrm{mmHg})$ & 4.53 & 17.63 & 3.36 & 17.17 & $0.01 *$ & $\mathrm{~A} \& \mathrm{~B}, \mathrm{~A} \& \mathrm{C}, \mathrm{B} \& \mathrm{C}$ \\
\hline $\mathrm{DBP}(\mathrm{mmHg})$ & 0.20 & 10.77 & 4.88 & 3.11 & $0.05 *$ & $\mathrm{~A} \& \mathrm{~B}, \mathrm{~A} \& \mathrm{C}, \mathrm{B} \& \mathrm{C}$ \\
\hline $\mathrm{HR}$ (beats/min) & 3.93 & 10.38 & 7.86 & 72.4 & $0.01 *$ & $\mathrm{~A} \& \mathrm{~B}, \mathrm{~A} \& \mathrm{C}, \mathrm{B} \& \mathrm{C}$ \\
\hline $\mathrm{RPP}$ (beats $/ \mathrm{min} / \mathrm{mmHg}$ ) & 906.91 & 3101.63 & 631.93 & 0.38 & 0.68 & \\
\hline \multicolumn{7}{|l|}{ Pulmonary } \\
\hline $\mathrm{RR}$ (counts/min) & 2.73 & 1.38 & 1.80 & 0.78 & 0.46 & \\
\hline $\operatorname{PEFR}(\mathrm{L} / \mathrm{min})$ & 28.34 & 17.62 & 20.39 & 0.83 & 0.44 & \\
\hline $\mathrm{FEV}_{1}(\mathrm{~L})$ & 0.41 & 0.18 & 0.22 & 3.50 & $0.03 *$ & $\mathrm{~A} \& \mathrm{~B}, \mathrm{~A} \& \mathrm{C}, \mathrm{B} \& \mathrm{C}$ \\
\hline $\mathrm{FVC}(\mathrm{L})$ & 0.40 & 0.24 & 0.19 & 8.31 & $0.01 *$ & $\mathrm{~A} \& \mathrm{~B}, \mathrm{~A} \& \mathrm{C}, \mathrm{B} \& \mathrm{C}$ \\
\hline FEV \% & 9.97 & 1.63 & 6.28 & 11.37 & $0.01 *$ & $\mathrm{~A} \& \mathrm{~B}, \mathrm{~A} \& \mathrm{C}, \mathrm{B} \& \mathrm{C}$ \\
\hline $\mathrm{IC}(\mathrm{mL})$ & 336.66 & 148.18 & 140.70 & 12.38 & $0.01 *$ & $\mathrm{~A} \& \mathrm{~B}, \mathrm{~A} \& \mathrm{C}, \mathrm{B} \& \mathrm{C}$ \\
\hline
\end{tabular}

*Significant difference at $\mathrm{p} \leq 0.05$

Key: SBP $=$ Systolic Blood Pressure; DBP $=$ Diastolic Blood Pressure RPP $=$ Rate Product Pressure HR $=$ Heart Rate; A $=$ Aerobic exercise group; B =

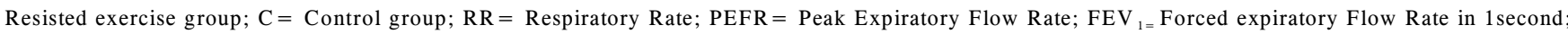
$\mathrm{FVC}=$ Forced Vital Capacity; $\mathrm{FEV}_{1} \%=\mathrm{FEV} / \mathrm{FVC}$ percent; IC = Inspiratory Capacity; ANOVA = Analysis of Variance

\section{DISCUSSION}

The aim of this study was to compare the effects of aerobic and resisted exercises on selected cardiopulmonary parameters in patients with asthma. The results show that after 6 weeks of exercise intervention, there were significant improvements in the selected pulmonary parameters of subjects in group A while there were no significant improvements in their cardiovascular parameters. There were significant improvements in selected cardiovascular parameters of subjects in group B while changes in their pulmonary parameters were not significant. Comparison of the mean changes in the cardiopulmonary variables between groups A and B showed significant differences in SBP, DBP, RPP, RR, FEV ${ }_{1}$, FVC, $\mathrm{FEV}_{1}$ and IC.

\section{Cardiovascular Variables}

The finding that there were no significant improvements in the selected cardiovascular variables of subjects in group A implies that aerobic exercise did not bring about any significant change in the cardiovascular variables. This may have to do with the dosage of the exercise given ( 2 times weekly for 6 weeks) since aerobic exercise is known to improve the cardiovascular parameters of individuals. Sembulingam and Sembulingam (2010) reported that aerobic exercise of low to moderate intensity and higher duration had a significant effect on systolic blood pressure but the diastolic blood pressure and heart rate did not change. This is because during dynamic exercise the peripheral resistance is altered and decreased depending on the intensity of the exercise. Since there was no significant change in either SBP or HR, there was also no significant change in RPP, as RPP is a product of SBP and HR.

Moez et al (2013) believe that improved aerobic performance is possible by modifying specific training programmes with regard to the frequency, duration, and intensity of exercise. However, the American Thoracic Society (ATS) and the American College of Chest Physicians (ACCP) (ATS, 1999; ATS/ACCP, 2003) speculated that a two sessions per week programme might not be as effective as more frequent exercise sessions. Also Cochrane and Clark (1990), Fink et al. (1993) and McArdle et al. (1996) found that the initial grade of fitness and motivation is an important predictor of aerobic improvement after training. Nevertheless, as previously observed, higher potential for improvement in the most 
unfit individual is a well-known phenomenon (Alberto et al., 1999). Similar findings were made by Alberto et al. (1999), who studied the short-term effects of aerobic training in the clinical management of moderate to severe asthma in adolescents for 6 weeks and reported that there were no significant differences in the cardiovascular parameters assessed. However, Fanelli et al (2007), who studied the effect of exercise training on disease control and quality of life in children with asthma, observed that there was a significant difference in their cardiovascular response after 16-20 weeks of exercise training performed 3 times per week. This may be due to higher frequency and duration of aerobic training.

The finding that there were significant improvements in the cardiovascular variables of subjects in Group B implies that resisted exercise brought about significant changes in these variables. Physiologically, performing resisted exercise over a period of time is likely to cause an increase in the SBP, HR and DBP of an individual because of an increase in peripheral resistance and decrease in stroke volume (Sembulingan and Sembulingam, 2010).

Although not much is known about resisted exercise in individuals with chronic lung disease, Simpsons et al. (1992) observed that improvement in anaerobic exercise tolerance led to improvement in the aerobic capacity of individuals with COPD.

Physiologically, endurance training is associated with increased cardiac output and volume load on the left and right ventricles, causing the endurance-trained heart to develop a mild to moderate increase in left ventricular wall thickness that is called eccentric left ventricular hypertrophy (Fogard, 2003).

Up until recently, the exercise limitation in patients with asthma was measured through aerobic exercise testing (Counil et al., 2001). During this type of exercise, it is acknowledged that the limitation in oxygen consumption is of ventilatory origin or due to detraining effects on the muscle cells (Varray and Prefaut, 1992; Prefaut et al., 1995). Since anaerobic and aerobic metabolisms are inextricably linked, it is difficult to assess the detraining effects of muscle cells and how it affects muscle cell function (Counil et al, 2001). Furthermore, Ghanbarzadeh and Fatemeh (2012) suggested that anaerobic exercise programmes should be included in the treatment of women with asthma because they observed that anaerobic programme significantly improved the subjects' aerobic capacity.
On comparing the effects of aerobic exercise and resisted exercise on the cardiovascular variables of patients with asthma, this study revealed that resisted exercise brought about more significant improvement than aerobic exercise.

\section{Pulmonary variables}

The finding that there were significant improvements in selected pulmonary variables of subjects in group A implies that aerobic exercise did bring about significant changes in most of the pulmonary variables $\left(\mathrm{FEV}_{1}, \mathrm{FVC}, \mathrm{FEV}_{1} \%\right.$, RR) except PEFR and IC. Physiologically, RR is bound to increase as a result of hyperventilation which includes an increase in the rate and force of respiration after an exercise protocol (Sembulingam and Sembulingam, 2010). Sembulingam and Sembulingam (2010) suggested that RR increases to about 30 counts per minute during moderate aerobic exercise and factors like chemoreceptors, higher centres, proprioceptors, acidosis, and body temperatures are responsible for the change in pulmonary ventilation. It drops after a while due to an increase in blood volume. Physiologically, the muscle cells in the body use up more oxygen and produce more carbon dioxide during exercise. The lungs have to work harder to provide oxygen and also remove carbon dioxide. There is an increase in the respiratory rate as the body tries to get as much oxygen as possible to minimize the amount of oxygen deficit. The muscles of the respiratory system, such as the diaphragm and intercostal muscles, get stronger. This makes the chest cavity larger during respiration thereby causing more air to be inspired. In addition, more capillaries are formed around the alveoli so that more gaseous exchange can take place (Guyton and Hall, 2006).

This finding corroborates previous studies that reported that there were significant differences in $\mathrm{FEV}_{1}$ and $\mathrm{FEV} \%$ post intervention (Cochrane and Clark, 1990; Emtner et al, 1996; Fatemi and Ghanbarzadeh, 2010). Fatemi and Ghanbarzadeh (2010) reported significant changes in $\mathrm{FEV}_{1}$ and FEV\% variables following exercise test protocol in young patients with asthma. Emtner et al (1996) studied high-intensity physical training in 26 adults with mild to moderate asthma and observed that there was a decrease in heart rate, significant increase in $\mathrm{FEV}_{1}$ from $2.2 \mathrm{~L}$ to $2.5 \mathrm{~L}$. Forced vital capacity also increased slightly but significantly; however, no improvement was observed in PEFR. 
However, the results of this study differed from those of Satta (2000) and Fanelli et al (2007) who concluded that there were no improvements in lung function after exercise training of any kind. Satta (2000) studied the effects of exercise training on the pulmonary functions of patients with asthma, while Fanelli et al (2007) observed the effects of exercise training on disease control and quality of life in patients with asthma. Both studies observed no significant improvements in pulmonary variables. Interestingly, all conflicting studies had smaller sample sizes and assessed only FEV ${ }_{1}$ and/or FVC. Fanelli et al (2007), who observed the effects of exercise training on disease control and quality of life in children with asthma, measured only $\mathrm{FEV}_{1}$. Also, different sample and protocol type may be partly responsible for the inconsistencies in the results. However, Bauerle and Younes (1995) in a study to determine exercise capacity in patients with COPD, observed that a decrease in inspiratory capacity correlated with aerobic exercise performance when they studied the role of ventilator response to exercise.

The finding that pulmonary variables in group B were not significant implies that resisted exercise did not bring about any significant improvement in patients with asthma. This observation, which is consistent with the results of several previous studies such as Satta (2000), Ram et al. (2005) and Fanelli et al. (2007), showed that there were no significant changes in any of the variables for lung function after exercise training as well as when compared with the control group. A systematic review of studies on exercise and asthma revealed that 9 out of the 13 that assessed lung function $\left(\mathrm{FEV}_{1}\right.$ and $\left.\mathrm{FVC}\right)$ found no changes following exercise intervention (Ram et al., 2005). All studies included in the review had subjects undergo 20-30 minutes of exercises, 2-3 times per week for 4 weeks.

On comparing the effects of aerobic exercise and resisted exercise on pulmonary variables of patients with asthma, this study revealed that aerobic exercise brought about more significant improvements than resisted exercise.

\section{CONCLUSION}

Aerobic exercise was more effective in improving the pulmonary variables of patients with asthma while resisted exercise was more effective in improving the cardiovascular variables of patients with asthma. Therefore therapeutic exercises such as aerobic and resisted exercises should be included as adjunct therapy by clinicians in the management of asthma.

\section{References}

Alberto J.N., E. Luiz, C. Antinio, C. Silva, L. Anna, B. Cabral , L. Ana, G. Fernandez. 1999. Short term effects of aerobic training in the clinical management of moderate to severe asthma in children. Thorax 54: 202-206.

American Thoracic Society (ATS). 1999. Pulmonary rehabilitation. American Journal of Respiratory Critical Care Medicine 159: 1666-1682.

American Thoracic Society/American College of Chest Physicians (ATS/ACCP). 2003. Statement on cardiopulmonary exercise testing. American Journal of Respiratory Critical Care Medicine 2: 211-277.

Andersen L.J., Randers M.B., Westh K., Martone D., Hansen P.R., Junge A., Dvorak J., Bangsbo J. and Krustrup P. 2010. Football as a treatment for hypertension in untrained 30-55year old men: a prospective randomized study. Scandinavian Journal of Medicine and Science in Sports 20 Suppl 1: 98-102.

Bauerle O. and Younes M. 1995. Role of ventilator response to exercise in determining exercise capacity in COPD. Journal of Applied Physiology 79(6): 1870-1877.

Beeh K.M. 2006. Cigarette smoking, but not sensitization to Alternaria, is associated with severe asthma in urban patients. Journal of Asthma 38: 41-49.

Bumgardner W. 2008. Walking workout-maximum heart rate. About.com Guide. Updated December, 2008, reviewed by Medical Review Board.

Cochrane L. and Clark C. 1990. Benefits and problems of a physical training program for asthmatic patients. Thorax Journal 5: 345-351.

Cohen L., Elias J. and Chupp G. 2004. Mechanism of asthma disease persistence and progression. Annals Review of Immunology 22: 789-815.

Counil F., C. Karila, A. Varray, S. Guillaumont, M. Voisin, C. Prefaut. 2001. Anaerobic fitness in children with asthma; adaptation to maximal intermittent short exercise. Journal of Pediatric Pulmonology 31: 198-204.

Emtner M, Herala M. and Stalenheim G. 1996. High-intensity physical training in adults with asthma. A 10-week rehabilitation program. Chest 2: 323-330.

Fatemi R. and Ghanbarzadeh M. 2010. Assessment of airway resistance indexes and exercise-induced asthma after a single session of submaximal incremental aerobic exercise. Journal of Human Kinetics 25: 59-65.

Fanelli A., Cabral A., Neder J., Martins M. and Carvalho C. 2007. Exercise training on disease control and quality of life in asthmatic children. Journal of Medicine and Science in Sports and Exercise 9: 1474-1480.

Fink G, Kaye C. and Blau H. 1993. Assessment of exercise capacity in asthmatic children with various degrees of activity. Pediatric Pulmonology 15: 41-43.

Fogard R. 2003. Athlete's heart. Heart 89: 1455-1461. 
Ghanbarzadeh M. and Fatemeh Z. 2012. The comparison of maximal aerobic and aerobic exercise on airway resistance indexes. International Journal of Sport Studies 2(5): 227-232.

Global Strategy for Asthma Management and Prevention. Global Initiative for Asthma (GINA). 2012.

http://www.ginasthma.org. Accessed on 18/08/2013.

Guyton, Arthur C. and Hall J.E. 2006. Textbook of Medical Physiology (11 ${ }^{\text {th }}$ Edition). Elsevier Saunders. 1050.

Janson C. 2004. The European Community Respiratory Health Survey; What are the main results so far? European Respiratory Journal 18: 598-611.

Lavoie K., Cartier A., Labrecque M., Bacon S., Lemiere C., and Malo J. 2005. Are psychiatric disorders associated with worse asthma control and quality of life in asthma patients? Respiratory Medicine Journal 10: 1249-1257.

McArdle W., Katch F. and Katch V. 1996. Training for Aerobic and Anaerobic Power: Exercise physiology. (4th Edition), Baltimore: William and Wilkin. 393-415.

Moez T., Haithem R., Mohammed S., Kaouthar M., Nicole F., Hel Z., Nouri Z., Zouhair T.. 2013. A comparative study of aerobic performance between football and judo group in prepubertal boys. Asian Journal of Sport Medicine 3: 165-174.

Parronchi P., Brugnolo F., Sampognaro S., and Maggi E. 2006. Genetic and environmental factors contributing to the onset of allergic disorders. International Arch Allergy Immunology 121: 2-9.

Prefaut C., Varray A. and Vallet G. 1995. Pathophysiology basis of exercise training in patients with chronic obstructive disease. Respiratory Revolution 5: 27-32.

Ram F., Robinson S., Black P., and Picot J. 2005. Physical training for asthma. Cochrane Database System Review 4: CD001116.

Russell B., Jeremy S., Breit M. and Stephen P. 2008. Allergic bronchopulmonary asthma. The Merck Manual of Health Professionals. 23-29.

Satta A. 2000. Exercise training in asthma. Journal of Sport Medicine and Physical Fitness 4: 277-283.

Sembulingam K. and Sembulingam P. 2010. Essentials of Medical Physiology (5 ${ }^{\text {th }}$ Edition). New Delhi: Jaypee Brothers Medical Publishers. 719-722.

Simpsons K, Killian K., MacCartney D., Stubbing G., Jones N.. 1992. Randomized control trial in weight-lifting exercise in patients with chronic airflow limitation. Thorax 47: 70-75.

Stores G., Ellis A.J. and Wiggs L. 1998. Sleep and psychological disturbance in nocturnal asthma. Arch Diseases in Children 78: 413-419.

Sullivan S.D., Wenzel S.E., Bresnahan B.W., Zheng B., Lee J.H., Pritchard M., Kamath T.V., Weiss S.T., TENOR Study Group. 2007. Association of control and risk of severe asthmarelated events in severe or difficult-to-treat asthma patients. Allergy 62: 655-660.

Tanaka H., Monahan K.D. and Seals D.R. 2001. Age-predicted maximal heart rate revisited. Journal of the American College of Cardiology 37(1): 153-156.

Varray A. and Prefaut C. 1992. Importance of physical exercise training in asthmatics. Journal of Asthma 29: 229-234. 